
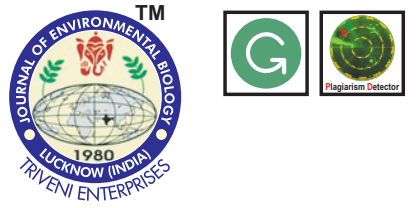

DOI : http://doi.org/10.22438/jeb/38/6/MRN-282

\title{
Studies on taxonomic diversity of plant communities and modeling its potential distribution in Yazılı Canyon Nature Park, Turkey
}

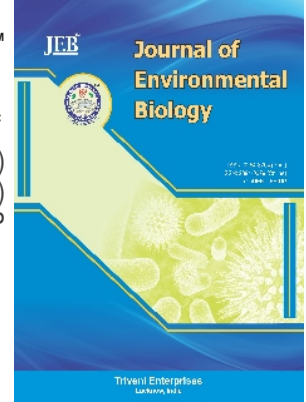

\section{Authors Info}

\section{A. Mert" and K. Özkan ${ }^{2}$}

'Department of Wildlife Ecology and Managment, Faculty of Forestry, Suleyman Demirel University, 32260, Isparta, Turkey

${ }^{2}$ Department of Soil Science and Ecology, Faculty of Forestry, Suleyman Demirel University, 32260, Isparta, Turkey

*Corresponding Author Email : ahmetmert@sdu.edu.tr.

\section{Key words}

Diversity indices

Modeling

Plant community

Regression tree technique

Taxonomic diversity

Publication Info

Paper received : 02.03 .2016

Revised received : 30.08 .2016

Re-revised received : 22.12.2016

Accepted: 10.05.2017

\section{Abstract}

Aim : The objective of the present study was to generate taxonomic diversity of plant communities and modeling its potential distribution in Yazilı Canyon Nature Park (Turkey).

Methodology : In the present study, taxonomic plant diversity were measured from the data obtained from 107 sampling plots and then modeled to visualize its' potential distribution by using regression tree technique (RTT) across the Yazilı Canyon Nature Park situated in the Mediterranean region, Turkey.

Results : Taxonomic diversity values were between 3.427 and 4.459 . The variables made up the regression tree model were slope (\%), distance to stream, solar illumination, altitude and aspect. The explained variances of tree models were unexpectedly found low with the values of $31.05 \%$ and $24.21 \%$ for training and testing data.

Interpretation : Even though tree model does not have high explanation ability, it was visualized to see the potential distribution of the taxonomic diversity in the study area. The distribution map illustrated that the places immediate environment to Yazilı stream and highly very steep places of the canyon has more taxonomic diversity values than its' other parts. This result was found meaningful since those places are more humid and include the plant species having more taxonomic distances from each other compared to its' other parts.

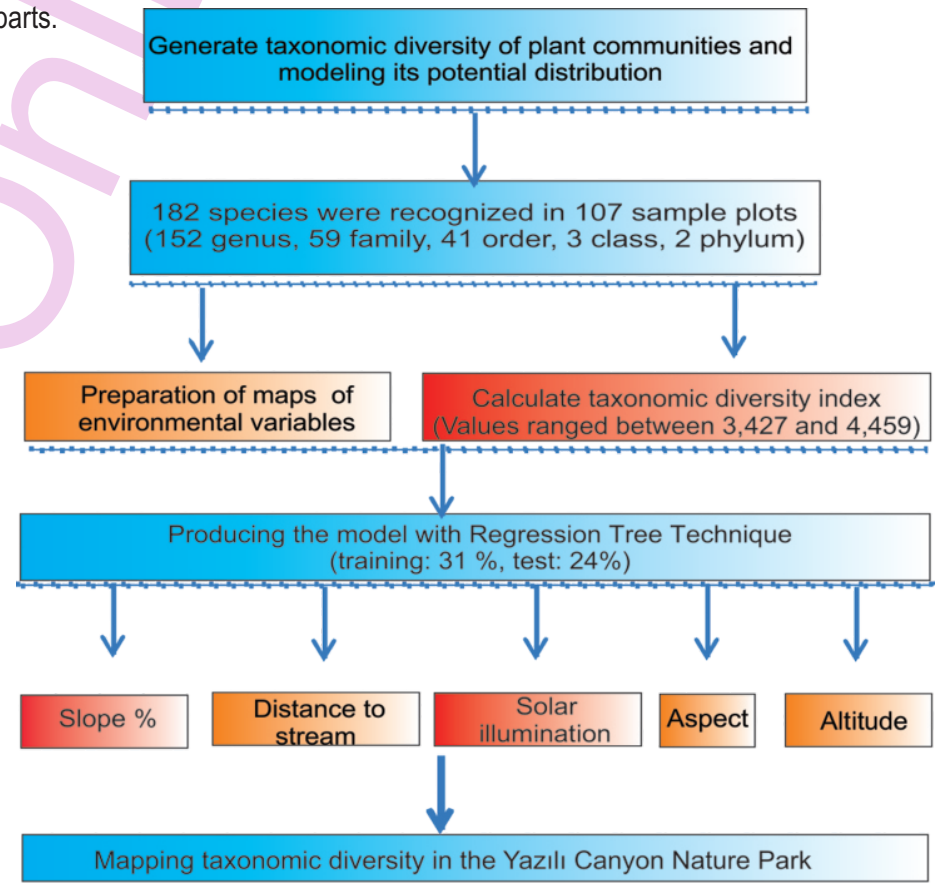




\section{Introduction}

Various indices have been used in defining biodiversity in conservation biology and community ecology (Gülsoy and Özkan, 2008; Özdemir and Karnieli, 2011). Those indices are divided mainly into two groups, which are traditional diversity indices and character based diversity indices. Among traditional diversity indices, the most popular ones are Shannon-Wiener entropy, Simpson dominance, Margalef index and Brillion index (Chiarucci et al., 2011; Svensson et al., 2012; Bandeira et al., 2013; Magurran, 2013). Character based diversity indices are known functional diversity and taxonomic diversity indices. Measuring functional diversity of living communities requires data about functional trails of the species. However, knowing the places in taxonomic hierarchy of the species is sufficient for measuring taxonomic diversity. In addition to this, taxonomic diversity is highly related to functional diversity, as well as species diversity of living communities (Özkan, 2012).

The explanations dealing with calculating taxonomic diversity for living communities were given by Warwick and Clarke (1995, 1998) and Clarke and Warwick (1998, 1999, 2001). These studies have attracted attention and, several researchers like Desrochers and Anand (2004), da Silva and Batalha (2006), YouHua and Zhi-Bo (2009), Koperski (2010) and Gwali et al. (2010) have preferred taxonomic diversity index for calculating biodiversity in their studies.

Even though advantages of taxonomic diversity has been well-explained by Warwick and Clarke $(1995,1998)$. Traditional diversity indices are still being used often in determining biodiversity than taxonomic diversity index. The reasons are probably due to fact that calculating taxonomic diversity is more complex than calculating biodiversity by using traditional diversity indices, preparing data for measuring taxonomic diversity is a long time consuming process, all species considered should be identified at species level to measure taxonomic diversity and the number of statistical package programs including measuring taxonomic diversity is insufficient. Due to these probable reasons, a study about modeling and mapping of taxonomic diversity has not been generated in forest ecosystems so far. On view of the above, the present study was carried out to generate taxonomic diversity of plant communities and modeling its potential distribution in Yazılı Canyon Nature Park, Turkey.

\section{Materials and Methods}

Study area : The data was obtained from Yazılı Canyon Nature Park, situated in the Mediterranean region of Turkey (Fig.1). The study area has a typical Mediterranean climate (dry-hot summers/ rainy winters). arth average annual precipitation if $950 \mathrm{~mm}$. The most arid and hottest months are July and August (with an annual average temperature of $13.1^{\circ} \mathrm{C}$, and $54 \%$ average relative humidity). Heavy rains occur in November, December, January and February, while water deficit extends from June to midOctober (DMl, 2006). The canyon is a short $(\sim 6 \mathrm{~km})$ deep limestone valley with a height varying between $100 \mathrm{~m}$ and $400 \mathrm{~m}$. Topography is irregular. Major soil types are brown forest soil, reddish-brown Mediterranean soil and reddish Mediterranean soil. Brutian pine (Pinus brutia Ten.) and Oak species (Quercus spp.) are dominant species in the forest. The nature park is rich in endemic species with twenty four endemic plant taxa (Özkan and Süel, 2008).

One hundred seven sample plots were surveyed in the Park (Fig. 1) and total of one hundred eighty two plant taxa were identified. The coverage of vascular plant taxa was documented according to Braun Blanquet method and transformed according to Whittaker (1973). All the datas were arranged and stored in Excel files for statistical analysis.

Response data : Taxonomic diversity index $\left(\Delta^{*}\right)$ is empirical relationship with Shannon -Wiener diversity but it has an added component of taxonomic separation. This index, as defined in Equation 1 was firstly employed by Warwick and Clarke (1995).

$$
\Delta=\frac{\sum_{i<j} W_{i j} x_{i} X_{j}}{\sum \sum_{i<j} x_{i} X_{j}+\sum_{i} x_{i}\left(x_{i}-1\right) / 2}
$$

where, $x_{i}$ and $x_{j}$ refers to numerical statement of the species abundances (e.g. number of individuals) and $w_{i j}$ refers to 'distinctness weight' given to the path length linking species $i$ and $j$ in the hierarchical classification.

Taxonomic diversity values of sample plots were calculated by Paleontological Statistics (PAST) software version 1.89 (Hammer et al., 2001).

Environmental data : All environmental variables were provided from digital elevation model belonging to study area. In this context, Digital elevation model (ELEVATION) was taken from General Directory of Forestry (OGM). Slope \% (SLOPE) and aspect (ASPECT) were created from the elevation built function provided using ArcGIS. Topographic position index (TPI) and landform category (LFC) maps were made from the elevation map by placing "tpi_jen.avx" file into the Arcview extensions directory (Weiss, 2001). Solar illumination index (SOLAR) map was derived using elevation map by Topography tools extension in ArcGIS 10.2. (Lyatsky et al., 2001). Distance to stream index (STREAMDS) map was obtained by calculating the distance from the points in the sampling design to nearest stream line in ArcGIS. Thereafter, these maps were resampled with a resolution of $20 \mathrm{~m}$ by $20 \mathrm{~m}$ grids using nearest neighbour interpolation as simplest technique for assigning pixel values to the new grid.

Radiation index (RI), used in the present study as an explanatory variable, was calculated for each pixel by the following equation (McCune and Keon, 2002) :

$$
\mathrm{RI}=\frac{[1-\cos ((\pi / 180)(\mathrm{Q}-30))]}{2}
$$

where, $\theta$ is an azimuth value measured from true north. This assigns a value of zero to land oriented in the north-north 
east direction (typically the coolest and wettest orientation) and a value of one on the hotter, drier south-south westerly slopes (Moisen and Frescino, 2002).

Modeling technique : Various modeling techniques are used in ecological researches. One of the most popular of them is regression tree technique (RTT) model. RTT is a non-parametric and nonlinear approach that is to partition the dataset into homogeneous subgroups with respect to same classes (Drapeau et al., 2000; Özkan et al., 2013; Özkan et al., 2015).

In regression trees, the response vector $(Y)$ represents the response values for each observation of the variable matrix $X$. Regarding impurity criterion, splits of a regression tree are performed in accordance with squared residuals minimization algorithm which implies that expected sum of variances for two resulting nodes should be minimized.

At each node, the regression tree solves the following minimization problem:

$$
\underset{x j \leq x}{\operatorname{Rrg}, j, j=1, \ldots . . M \quad \min } \quad\left[P_{,} \operatorname{Var}\left(Y_{i}\right)+P_{r} \operatorname{Var}\left(Y_{r}\right)\right]
$$

where, $P_{l}$ and $P_{r}$ are probabilities of left and right nodes. $M$ is the number of variables in learning sampling. $x_{j}$ is variable $j . x_{j}^{R}$ denotes best splitting value of variable $x_{j} \operatorname{Var}\left(Y_{i}\right), \operatorname{Var}(Y r)$ are response vectors for corresponding left and right child nodes. $x_{j} \leq x_{j}^{R}, j=1 \ldots, M$ means optimal splitting question which satisfies the condition.

Squared residuals minimization algorithm and Gini splitting rule are the same. When assigning to objects of class $k$ the value 1 , and value 0 to objects of other classes, sample variance of those values would be equal to $p(k \mid t)[1-p(k \mid t)]$. Summarizing by number of classes $K$, impurity measure $i(t)$ is found the following way.

$$
i(t)=1-\sum_{k=1}^{K} P^{2}(k \backslash t)
$$

where, $p(k \mid t)$ - conditional properties of class k provided in node $t$; $K$ - number of classes; $k$ - index of class and, $t$ - index of node.

Before applying the RTT, $30 \%$ of the data was separated for testing. Remaining data was used for modeling. The initial tree was pruned by testing set, where error rates were calculated for full tree in addition to smaller subtrees. Subtree with smallest error rate was then chosen as optimal tree for response variable, the coefficient of determination $\left(R^{2}\right)$ was used as a criterion to evaluate the model performances.

RTT were run by using DTEG (Sherrod, 2014). After running RTT, if-then rules were written for each path of tree graphs in Excel file to calculate the predicted values of response variable (Özkan and Berger, 2014).
The estimated values obtained from tree model were calculated at each grid $(20 \times 20 \mathrm{~m})$. All grids were digitalized to form a niche based distribution map of taxonomic diversity.

\section{Results and Discussion}

One hundred eighty two species recognized in the sample plots were represented by 152 genus, 59 family, 41 order, 3 class and 2 phylum in taxonomic hierarchy. The numerical values transformed according to Westhoff and van der Maarel (1973) of the species varied between 9 and 48 per plot (mean=29). The most highly speciose family was Asteraceae (23 species). Of the 182 species encountered, Daphne, Salvia, Sideritis, Trifolium and Verbascum were dominant.

Taxonomic diversity values varied between 3.427 and 4.459. RTT was applied for modeling the distribution of taxonomic diversity (response variable) by means of environmental factors (explanatory variables). The optimal regression tree of taxonomic diversity produced a tree with 6 terminal nodes and 4 splits (Fig. 2). The explained variances of tree model were $31 \%$ and $24 \%$ for training and testing data. Özkan and Berger (2014) studied the Yukarıgökdere forest district in the mountain zone of the Mediterranean region. To build a distribution model of species diversity, the researchers used RTT, and reported the explained variance of the distribution model as $63 \%$. Dogan and Dogan (2006) modeled plant species richness using by Simpson $D$ diversity index with multiple regression analysis in The Nallıhan district of Turkey. As a result of the study, a distribution model with an explanation rate of $59 \%$ was obtained. When comparing the results of the studies done by Özkan and Berger (2014) and Dogan and Dogan (2006), the explained variance value of the distribution model obtained from the present study seems to be remained insufficient. One of the reasons of insufficiency of the distribution model we obtained is probably related to scale of the study area. Because Yukarıgökdere Forest district and Nallıhan district are correspond to middle scale-area and large scale area, respectively. However Yazılı Canyon Nature Park is a small-scale area.

The second reason of the weakness of the model is probably related to considerable potential contribution of topographical heterogeneity to the distribution model. As explained by several researchers (MacArthur and MacArthur, 1961; Tilman, 1982; Palmer, 1992; Huston, 1994; Vivian-Smith, 1997; Crawley and Harral, 2001; Willis and Whittaker, 2002; Steiner and Köhler, 2003; Dufour et al., 2006), increasing biodiversity is often associated with greater environmental or topographical heterogeneity. In this regard, we may postulate that the variation of taxonomic diversity is not very sensitive in the variations of environmental variables among the sample plots level but environmental heterogeneity within sample plot. Unfortunately we did not measure the data belonging to micro habitat heterogeneity even though the study area has a high topographical variability due to its' irregular, karstic structure. That 


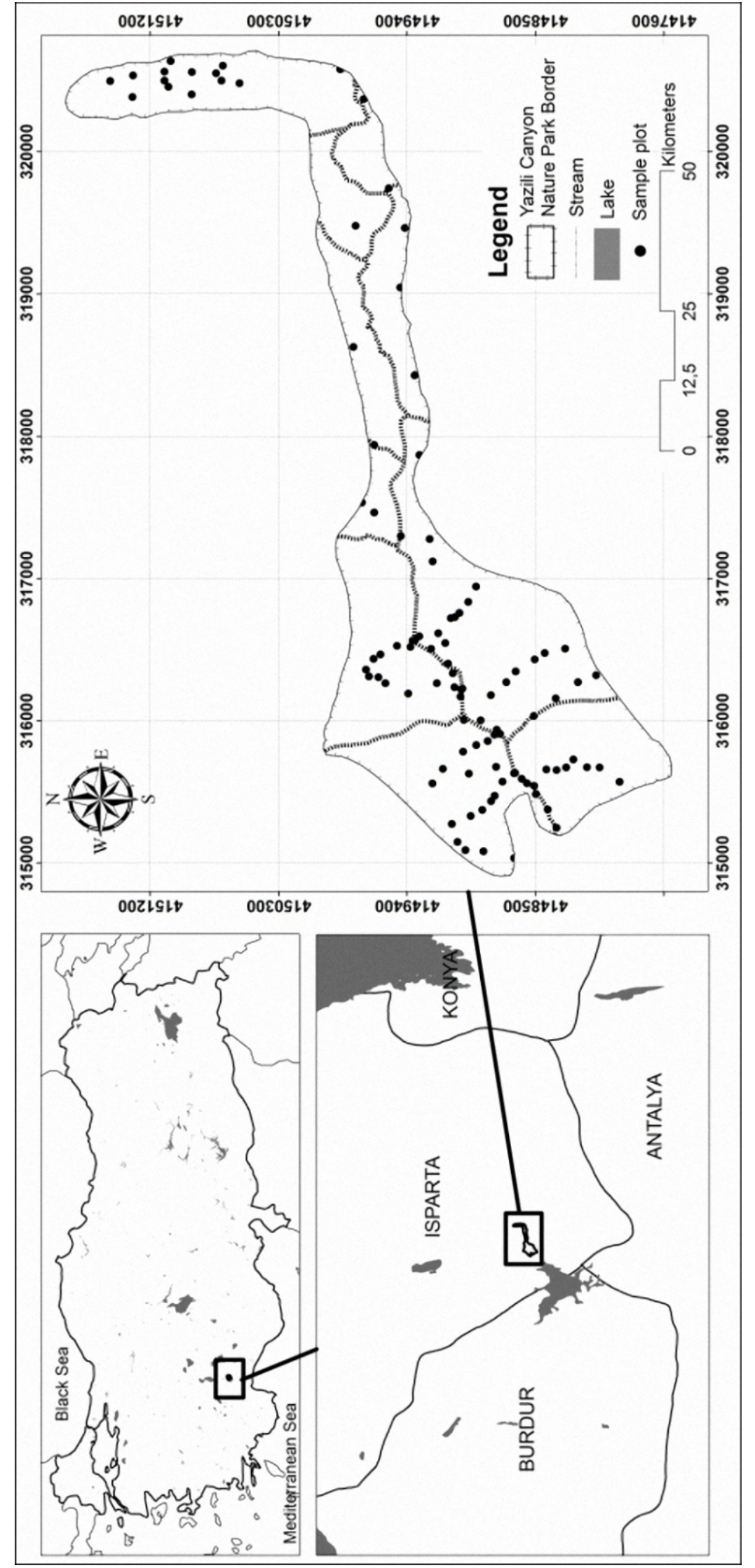

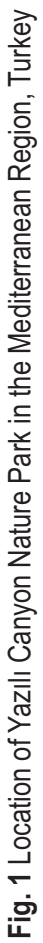




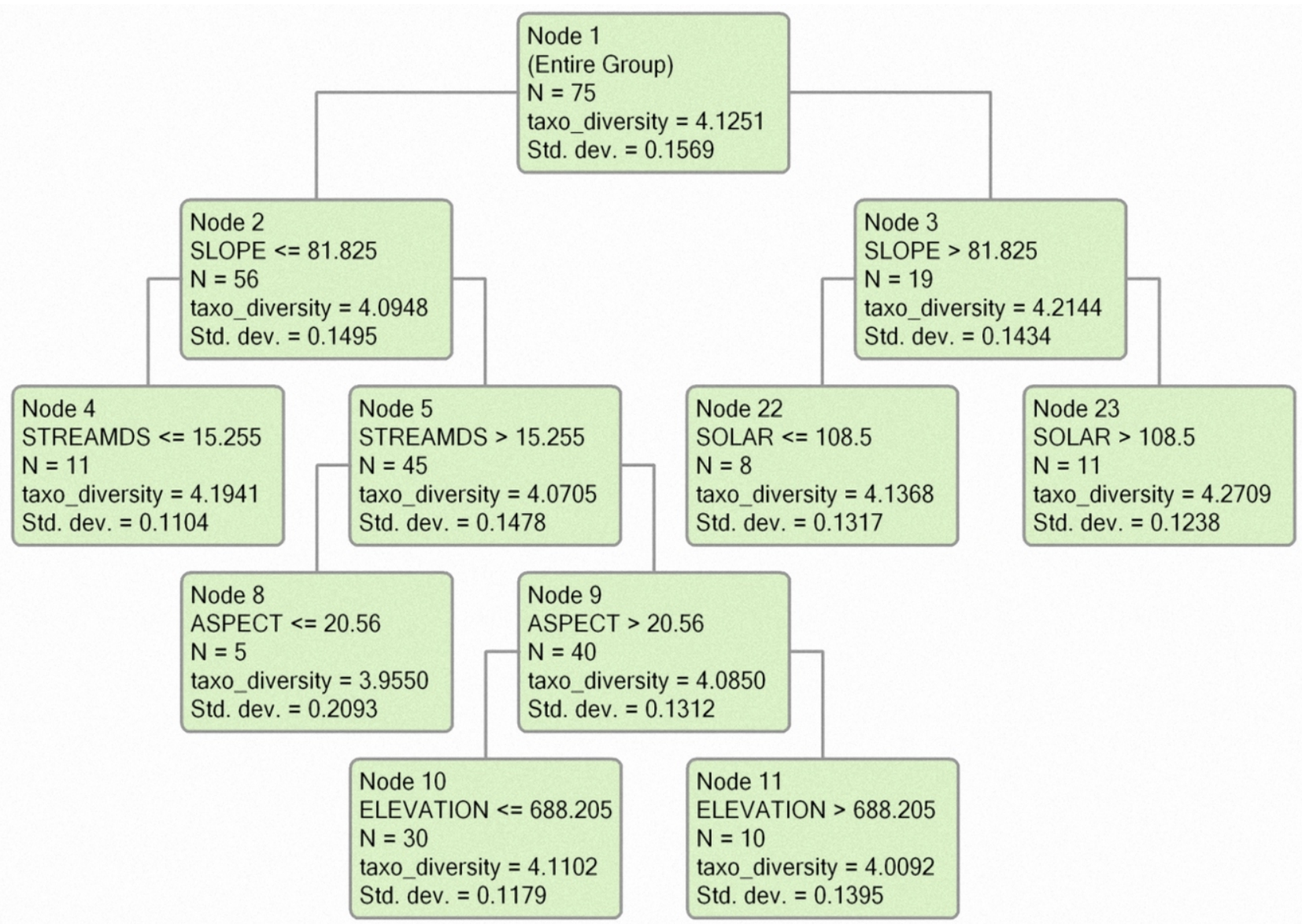

Fig. 2 : Fitted regression tree and estimated values of taxonomic diversity

is why we do not know how much micro habitat (topographical) heterogeneity within sample plot is significant to explain the variations of taxonomic diversity.

As Warwick and Clarke (1998), Heino et al. (2007) and Gwali et al. (2010) pointed out, taxonomic diversity index is appropriate to demonstrate the effect of anthropogenic disturbance and degradation of biotic communities. In this sense, it might be thought that insufficiently explanation variance of the distribution model is related to degradation. However; Yazılı Canyon Nature Park is a well-managed protected area, not subjected to anthropogenic disturbance for a long time.

On the context of the explanations above, to better explain the interrelationships between environmental factors and taxonomic diversity, further studies of taxonomic diversityenvironmental relations are clearly needed.

The tree model was created by slope $\%$, distance to stream, solar illumination, aspect and altitude. The highest $\Delta^{*}$ value occurred on plots with more than 81.825 of slope $\%$ and solar illumination greater than 108.5. Regarding the least $\Delta^{*}$ value, the environmental variables played roles were slope
$\%$ (less than 81.825), distance to stream (less than 15.255) and aspect (less than 20.56). Model based map of taxonomic diversity is shown in Fig. 2. As seen in the distribution map, the places immediate environment to middle and upper areas and very steep places of the canyon showed richer in taxonomic diversity values than other parts. According to a study carried out on endemic plant species in the Yazılı Canyon Nature Park (Özkan and Süel, 2008), estimating species diversity obtained from Simpson Reciprocal Index was found higher in the lower part, in particular, valley bottom of the Yazilı Canyon. As compared to the results of Özkan and Süel (2008) to the result of the present study, a negative correlation between species diversity and taxonomic diversity was noted. It is well-known that taxonomic diversity is calculated by using taxonomical distances (Desrochers and Anand, 2004; Da Silva and Batalha, 2006; You-Hua and Zhi-Bo, 2009; Koperski, 2010; Gwali et al., 2010) among the species, whereas species diversity is calculated by considering the number of species and their relative values when Shannon-Wienner index (Shannon, 1948) or Simpson reciprocal index (Simpson, 1949) are used. Such a negative relationship between taxonomic diversity and species diversity was not new, since woody and herbaceous species shows approximately uniform distribution (well-balanced 


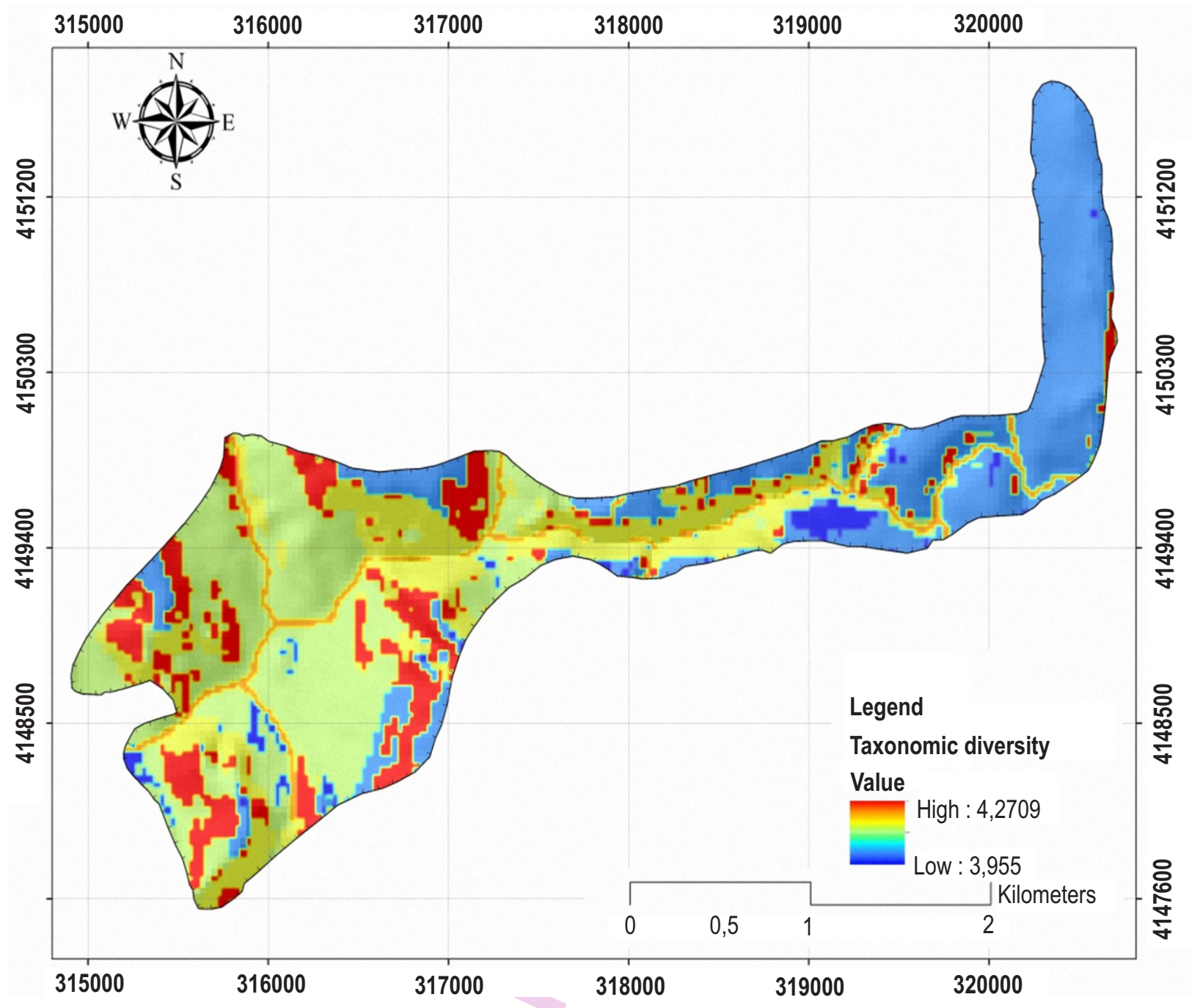

Fig. 3 : Spatial distribution modeling of $\Delta^{*}$ in the Yazılı Canyon Nature Park

distribution) in the upper part of the Canyon whereas majority of the species composed of herbaceous species in lower part of valley bottom of the study area.

Turkey resigned biodiversity convention in 1996 (Glowka et al., 1996). After signing this convention, the studies dealing with measuring biodiversity, examining biodiversity-environment relationships, and modeling and mapping of biodiversity using remote sensing data and GIS gained much more importance (Maddock and du Plessis, 1999; Özdemir and Donoghue, 2013; Özdemir, 2014). As mentioned before, diversity has been studied in different ways (Clarke and Warwick, 2001; Shimatani, 2001; Petchey et al., 2004; Ozkan, 2012; Negiz et al., 2015). Unlike the traditional diversity indices, taxonomic diversity is calculated considering the places in taxonomic hierarchy of the species. That is why taxonomic diversity is not related only to species diversity but also to functional diversity and genetic diversity among the species and structural diversity of vegetation communities (Özkan, 2012).

As a conclusion, taxonomic diversity index is a more suited equation to explain biodiversity than traditional diversity indices (Vane-Wright et al., 1991; Izsák and Papp,1995; Somerfield et al., 1997). The distribution maps of taxonomic diversity are, therefore, one of the most essential information layers intended for preparing and implementations of conservation and management plans to enable sustainability of the ecosystems.

\section{Acknowledgments}

We thank Prof. Serkan Gülsoy, Prof. Mehmet Güvenç Negiz and Prof. Halil Süel for their valuable contribution during our study. 


\section{References}

Bandeira, B., J., L. Jamet, D. Jamet and J. M. Ginoux: Mathematical convergences of biodiversity indices. Ecol. Indic., 29, 522-528 (2013).

Chiarucci, A., G. Bacaro and S.M. Scheiner: Old and new challenges in using species diversity for assessing biodiversity. Philos. Trans. $R$ Soc. Lond. Biol. Sci., 366, 2426-2437 (2011).

Clarke, K. R. and R. M. Warwick: A taxonomic distinctness index and its statistical properties. J. Appl. Ecol., 35, 523-531 (1998).

Clarke, K.R. and R.M. Warwick: The taxonomic distinctness measure of biodiversity: weighting of step lengths between hierarchical levels. Mar. Ecol. Prog. Ser., 184, 21-29 (1999).

Clarke, K.R. and R.M. Warwick: A further biodiversity index applicable to species lists: variation in taxonomic distinctness. Mar. Ecol. Prog. Ser., 216, 265-278 (2001).

Crawley, M. J. and J. E. Harral: Scale dependence in plant biodiversity. Science, 291, 864-868 (2001).

Da Silva, I. A. and M. A. Batalha: Taxonomic distinctness and diversity of a hyper seasonal savanna in central Brazil. Divers. Distrib., 12, 725-730 (2006).

Desrochers, R. and M. Anand: From traditional diversity indices to taxonomic diversity indices. Int. Ecol. Environ. Sci., 30, 85-92 (2004).

DMI: Government Meteorological Institute -Meteorological Data of Sütçüler District between 1975-1993. Sütçüler /lsparta, Turkey (2006).

Dogan, H. and M. Dogan : A new approach to diversity indices-modeling and mapping plant biodiversity of Nallihan (A3-Ankara/Turkey) forests ecosystem in frame of geographic information systems. Biodicon., 15, 855-878 (2006).

Drapeau P., A. Leduc and J.F. Giraux: Landscape-scale disturbances and changes in bird communities of boreal mixed-wood forests. Ecol. Monogr., 70, 423-444 (2000).

Dufour, A., F. Gadallah, H. H. Wagner, A. Guisan and A. Buttler: Plant species richness and environmental heterogeneity in a mountain landscape : effects of variability and spatial configuration. Ecography., 29, 573-584 (2006).

Gülsoy, S. and K. Özkan: Importance of biodiversity from the ecological standpoint and some diversity indexes. J. Fac. For. Suleyman Demirel University Publications, 1, 168-178 (2008).

Glowka, L., F. Burhenne-Guilmin and H. Synge: Guide to the convention on biological diversity. IUCN Gland and Cambridge, p.166 (1996).

Gwali, S., P. Okullo, D. Hafashimana and D. M. Byabashaija: Taxonomic diversity, distinctness, and abundance of tree and shrub species in Kasagala forest reserve in Uganda: Implications for management and conservation policy decisions. Trop. Conserv. Sci., 3, 319-333 (2010)

Hammer, Ø., D. A. T. Harper and P. D. Ryan: PAST: Palaeontological Statistics software package for education and data analysis. Palaeontol. Electron., 4, 9 (2001).

Heino, J., H. Mykr, J. Kotanen and T. Muotka: Ecological filters and variability in stream macroinvertebrate communities: Do taxonomic and functional structure follow the same path? Ecography, 30, 217-230 (2007).

Huston, M. A.: Biological diversity: The coexistence of species on changing landscapes. Cambridge University Press, pp. 397-404 (1994).

Izsák, J. and L. Papp: Application of the quadratic entropy index for diversity studies on drosophilid species assemblages. Environ. Ecol. Stat., 2, 213-224, (1995).

Koperski, P. : Diversity of macrobenthos in lowland streams: Ecological determinants and taxonomic specificity. J. Limmol., 69, 88-101 (2010).

Lyatsky, W., P. T. Newell and A. Hamza: Solar illumination as cause of the equinoctial preference for geomagnetic activity. Geophys. Res. Lett., 28, 2353-2356 (2001).

MacArthur, R. H. and J. W. MacArthur: On bird species diversity. Ecology, 42, 594-598 (1961)

McCune, B. and K. Dylan: Equations for potential annual direct incident radiation and heat load. J. Veg. Sci., 13, 603-606 (2002).

Maddock, A. and M. A. du Plessis: Can species data only be appropriately used to conserve biodiversity? Biodivers. Conserv., 8,603-615(1999)

Magurran, A. E.: Measuring biological diversity. Oxford : Blackwell Publishing, p. 256, (2013).

Moisen, G.G. and T.S. Frescino: Comparing five modelling techniques for predicting forest characteristics. Ecol. Model., 157, 209-225 (2002).

Negiz., M.G., S. Gülsoy and K. Özkan: An available field invantory approuch for calculation of species diversity components in forest ecosystems. J. Nat. Appl. Sci., 19, 198-204 (2015).

Özdemir, I. and A. Karnieli : Predicting forest structural parameters using the image texture derived from World View-2 multispectral imagery in a dryland forest, Israel. Int. J. Appl. Earth Obs. Geoinf., 13, 701 $710(2011)$

Özdemir, I. and D. N. Donoghue: Modelling tree size diversity from airborne laser scanning using canopy height models with image texture measures. For. Ecol. Manage., 295, 28-37 (2013).

Özdemir, I.: Linear transformation to minimize the effects of variability in understory to estimate percent tree canopy cover using Rapid Eye data. GI Science Remote Sensing, 51, 288-300 (2014).

Özkan, K.: Comparison of taxonomic diversity indices with traditional diversity indices. J. Fac. For. SDU., 13, 107-112 (2012).

Özkan, K. and U. Berger: Predicting the potential distribution of plant diversity in the Yukarigökdere forest district of the mediterranean region. Pol. J. Ecol., 62, 441-454 (2014).

Özkan, K., A. Mert, W. Aertsen and B. Muys: Hierarchical land classification and mapping of Ağlasun Forest Ecosystems in the Mediterranean Region, Turkey. J. Environ. Biol., 34, 623-633 (2013).

Özkan, K. and H. Süel : Endemic plant species in a karstic canyon (Mediterranean Region, Turkey): Relation to relief and vegetation diversity. Pol. J. Ecol., 56, 709-715 (2008).

Özkan, K., Ö. Şentürk, A. Mert and M.G. Negiz: Modeling and mapping potential distribution of Crimean juniper (Bieb.) using correlative approaches Juniperus excelsa Bieb.) using correlative approaches. J. Environ. Biol., Special issue, 36, 9-15(2015).

Palmer, M. W.: The coexistence of species in fractal landscapes. Am. Nat., 139, 375-397 (1992).

Petchey, O. L., A. Hector and K. J. Gaston: How do different measures of functional diversity perform. Ecology, 85, 847-857 (2004).

Shannon, C.E.: A mathematical theory of communication. Bell Syst. Tech. J., 27, 379-423 (1948).

Sherrod, P.H: "DTREG predictive modeling software", Users' Guide, 2003-2008, www.dtreg.com (2014).

Shimatani, K.: On the measurement of species diversity incorporating species differences. Oikos., 93, 135-147 (2001).

Simpson, E. H.: Measurement of diversity. Nature, 163, 688 (1949).

Somerfield, P. J., F. Olsgard and M. R. Carr.: A further examination of two new taxonomic distinctness measures. Mar. Ecol. Prog. Ser.,154, 303-306 (1997).

Steiner, N. C. and W. Köhler: Effects of landscape patterns on species richness: A modelling approach. Agricult. Ecosyst. Environ., 98, 
353-361 (2003).

Svensson, J. R., M. Lindegarth, P. R. Jonsson and H. Pavia: Disturbance-diversity models : What do they really predict and how are they tested? Proceedings of the royal society of London $B$. Biol. Sci., 279, 2163-2170 (2012).

Tilman, D.: Resource Competition and Community Structure. (Mpb-17). Princeton University Press Princeton, NJ : (1982).

Vane-Wright, R.I., C.J. Humphries and P.M. Williams: What to protect: Systematics and the agony of choice. Biol. Conserv., 55, 235-254 (1991).

Vivian-Smith, G.: Microtopographic heterogeneity and floristic diversity in experimental wetland communities. J. Ecol., 85, 71-82 (1997).

Warwick, R. M. and K. R. Clarke: New 'biodiversity' measures reveal a decrease in taxonomic distinctness with increasing stress. Mar. Ecol. Prog. Ser., 129, 301-305 (1995).

Warwick, R. M. and K. R. Clarke: Taxonomic distinctness and environmental assessment. J. Appl. Ecol., 35, 532-543 (1998).

Weiss, A.: Topographic position and landforms analysis (Poster presentation) ESRI User Conference, San Diego, CA, 9-13 (2001). Westhoff, V. and E. van der Maarel: The Braun-Blanquet Approuch. In: R.H. Whittaker, Handbook of Vegetation Science 5: Ordination and classification of communities. Junk, The Hague, Netherland, pp. 617-726 (1973).

Whittaker, R.H.: Ordination and Clasification of Communities (Part V). Handbook of Vegetation Science (Ed.: R. Tüxen). The Netherlands by Dijkstra Niemeyer b. v., Groningel, 5, 287-321 (1973).

Willis, K. J. and R. J. Whittaker : Species diversity scale matters. Science, 295, 1245-1248 (2002)

You-Hua, C. and W. Zhi-Bo: Relationship between taxonomic distinctness and environmental stress in terrestrial organisms at large spatial scale: A study for insect family Ceratopogonidae in East Asia. Acta. Zool. Bulg., 61, 69-77 (2009). 